\title{
Influência do Açúcar Invertido nos Biscoitos Modelados tipo Rosquinha
}

\author{
Kelly N. Marra, Mikaele L. S. Santos \& Daniela F. Silva
}

Buscando agradar os consumidores, as indústrias alimentícias apresentam uma variedade de novidades. Para alcançar as novidades, pode optar por acrescentar algum ingrediente ou fazer a troca de formulação. Foram elaborados dois diferentes ensaios de biscoitos, diferenciaram-se apenas no tipo de açúcar utilizado. A análise sensorial foi feita por teste de preferência utilizando o teste de comparação pareada- diferença (bicaudal) para analisar o resultado da análise. Conclui-se que a adição de açúcar invertido na formulação de biscoitos tem grande influência positiva nas características de sabor, aroma e textura do produto.

Palavras Chave: Biscoito, Açúcar Invertida, Analise Sensorial.

Seeking to please consumers, the food industries present a variety of novelties. To achieve the novelties, you can choose to add some ingredient or make the formulation change. Two different biscuit trials were developed, differing only in the type of sugar used. Sensory analysis was performed by preference test using the paired-difference (two-tailed) test to analyze the analysis result. It is concluded that the addition of invert sugar in the biscuit formulation has a great positive influence on the taste, aroma and texture characteristics of the product.

Keywords: Biscuit; Inverted Sugar, Sensory Analysis. 


\section{Introdução}

Buscando agradar os consumidores, cada vez mais exigentes, as indústrias alimentícias vêm a cada dia apresentando novidades e também aperfeiçoando os produtos que já oferecem, melhorando desde a embalagem ás características sensoriais do produto. O segmento de biscoitos é um exemplo, que possui uma grande variedade de produtos que passam por constantes modificações.

A Agência Nacional de Vigilância Sanitária (ANVISA) define biscoito ou bolachas como produtos obtidos pela mistura de farinha(s), amido(s) e/ou fécula(s) com outros ingredientes, submetidos a processos de amassamento e cocção, fermentados ou não. Podendo apresentar cobertura, recheio, formato e textura diversos" 1 .

Para alcançar o aperfeiçoamento e inovação dos produtos oferecidos, a indústria pode optar por acrescentar algum ingrediente ou fazer a troca de algum que já faça parte da formulação, visando tanto melhorias nas características sensoriais quanto um melhor custo benefício.

O termo biscoito deriva do latim bis coctus ou do francês bi-cuire, que significam duas vezes cozido. Tem origem provável no oriente médio, sendo que o mais antigo biscoito conhecido é o Matzohjudeu. A história do biscoito se confunde com a história das navegações. Biscoitos feitos basicamente com 36a Encontro Nacional dos Estudantes de Química - Goiânia - Goiás farinha, água e sal faziam parte da alimentação dos antigos marinheiros, principalmente quando os produtos perecíveis se extinguiam na embarcação. A confecção destes biscoitos, chamados de bolachas, era a forma de garantir uma maior durabilidade às farinhas de trigo e para facilitar seu consumo ${ }^{2}$.

Com base nessas definições os biscoitos podem ser classificados de diversas formas, essas classificações se tornam ainda mais expressivas quando se consideram as diferenças regionais. Segundo o Serviço Brasileiro de Respostas Técnicas (SBRT) existem, basicamente, três tipos de biscoitos: Biscoitos de massas duras (tendo como exemplo: produtos com baixo teor de proteína como Maria, Maizena etc), biscoitos de massas moles (produtos com teor de proteína médio, em torno de $9 \%$, como as rosquinhas), biscoitos de massas fermentadas (produtos com teor de proteína mais elevado, em torno de $11 \%$. Os mais conhecidos são o cream cracker e água e sal). Para o Sindicato da Indústria de Massas Alimentícias e Biscoitos no Estado de São Paulo (SIMABESP) as variedades de biscoitos podem ser divididas em: biscoitos salgados; doces; recheados; revestidos; grissini; biscoitos para aperitivos e petiscos ou salgadinhos; palitos para salgadinhos ou pretzel, wafer, wafer recheado e petit- four. ${ }^{3}$

A Comissão Nacional de Normas e Padrões para Alimentos em sua Resolução CNNPA n ${ }^{\circ} 12$ de 1978 define: açúcar é a sacarose obtida de Saccharumofficinarum, ou de Beta alba, L., por processos industriais adequados. O produto é designado "açúcar", seguido da denominação correspondente às suas características. Ex: "açúcar cristal", "açúcar mascavo"4.

$\mathrm{O}$ açúcar refinado invertido é um açúcar líquido refinado obtido através da inversão da sacarose. Possui a denominação "invertido" porque inverte a rotação da luz polarizada em um equipamento denominado polarímetro. Medindo-se o ângulo de desvio da luz polarizada durante o processo de obtenção do açúcar invertido, observa-se que ocorre a variação de um valor positivo no início da hidrólise (reação com água catalisada por aquecimento e por um ácido, enzima ou resina) para um valor negativo após a reação, justificando a denominação do processo de inversão .

A quantidade, a granulação e o tipo de açúcar usado influenciam muito a qualidade do produto. $\mathrm{O}$ aumento da concentração de açúcar geralmente aumenta o espalhamento e a pegajosidade, além de reduzir a espessura dos biscoitos ${ }^{6}$.

A combinação de açúcares atua de forma ainda mais efetiva no produto, um exemplo é a combinação da sacarose com o açúcar invertido na produção dos biscoitos que atua na melhoria da cor e aroma, pois o açúcar invertido é responsável por uma reação importante na etapa de forneamento que é a Reação de Maillard. Essa reação geralmente ocorre entre o grupo amina livre de aminoácidos ou outras moléculas e a carbonila de açúcares redutores como a glicose e a frutose, o que confere sabor, aroma e cor característicos e determinantes na escolha pelo consumidor? 
Diante do exposto, o objetivo do trabalho foi analisar a influência da utilização de açúcar invertido na produção de biscoitos tipo rosquinhas, e identificar a preferência do público entre um biscoito formulado apenas com sacarose $\mathrm{e}$ um contendo combinação de sacarose com açúcar invertido, através de análise sensorial.

\section{Metodologia}

Foram elaborados dois diferentes ensaios de biscoitos modelados tipo rosquinha, com base na formulação da tabela 1. O biscoito (tipo I) e (tipo II) diferenciaram-se apenas no tipo de açúcar utilizado, sendo que no (tipo I) utilizou-se apenas sacarose e no (tipo II) utilizou-se uma combinação de sacarose com açúcar invertido.

Tabela 1. Formulação para a produção do biscoito.

\begin{tabular}{|c|c|c|}
\hline $\begin{array}{c}\text { INGREDIENTE } \\
(\% / \mathrm{Kg})\end{array}$ & $\begin{array}{c}\text { BISCOITO TIPO I } \\
(151)\end{array}$ & $\begin{array}{c}\text { BISCOITO TIPO II } \\
(989)\end{array}$ \\
\hline Água & 8,6 & 8,6 \\
\hline Lecitina & 0,57 & 0,57 \\
\hline Farinha & 49,11 & 49,11 \\
\hline Amido & 1,9 & 1,9 \\
\hline Aroma & 0,26 & 0,26 \\
\hline Gordura & 8,03 & 8,03 \\
\hline Sal & 0,57 & 0,57 \\
\hline $\begin{array}{c}\text { Bicarbonato de } \\
\text { sódio }\end{array}$ & 0,21 & 0,21 \\
\hline $\begin{array}{c}\text { Bicarbonato de } \\
\text { amônia }\end{array}$ & 0,15 & 0,15 \\
\hline Aḉcar invertido & 0 & 5,35 \\
\hline Sacarose & 30,6 & 25,25 \\
\hline
\end{tabular}

Os biscoitos foram produzidos de forma artesanal, os ingredientes foram pesados previamente em balança analítica na Universidade Estadual de Goiás (UEG). Após a modelagem, feita manualmente, eles foram assados á uma temperatura de $200^{\circ} \mathrm{C}$ com uma média de tempo de 8 minutos para cada fornada de 30 biscoitos.
A análise sensorial foi realizada na Universidade Estadual de Goiás ( UEG ) utilizando teste de preferência pareada, com 100 provadores não treinados com idade entre 19 e 25 anos. Os provadores receberam uma amostra de cada ensaio dos biscoitos modelados tipo rosquinha, cada ensaio foi embalado individualmente e cada um recebeu um código. Juntamente com as amostras receberam um copo com água, caneta e a ficha de avaliação com as instruções para preenchimento. Eles foram orientados a degustar as amostras, tomando água entre um ensaio e outro, e circularem na ficha o código da amostra que mais gostaram de maneira geral (cor, sabor, aroma).

\section{Resultados e Discussão}

A análise sensorial foi feita por teste de preferência utilizando o teste de comparação pareada- diferença (bicaudal) para analisar o resultado da análise. Obteve-se 100 respostas para a análise, sendo que destas 61 preferiram o biscoito ( tipo II ) com código 989 e 39 preferiram o biscoito ( tipo I ) com código 151.

$\mathrm{O}$ biscoito ( tipo II ) foi significativamente preferido em relação ao biscoito (tipo I) ao nível de significância de 5\%, de acordo com a tabela 2. E essa preferência foi justificada por muitas pessoas durante a realização da análise sensorial, muitas pessoas alegaram que, o biscoito tipo II que foi apresentado a eles com código 989, além de mais doce ele apresentava aroma e textura nitidamente mais agradável do que o biscoito tipo I e por essas características o preferiram. Já os provadores que preferiram o biscoito tipo I, coerentemente, informaram que o preferiram por ser menos doce, mas não fizeram comentário sobre aroma nem textura deste.

O que justifica o melhor sabor, aroma e textura alegado pelos provadores em relação ao biscoito (tipo II), é a presença do açúcar invertido na sua formulação. Este tipo de açúcar tem característica de ser mais doce do que o açúcar cristal (sacarose), isso se deve á elevada solubilidade da glicose e frutose em água no processo de hidrólise para a produção do açúcar invertido, dando assim ao açúcar invertido a propriedade de ser aproximadamente $20 \%$ mais doce que a sacarose, o que agradou a maioria dos provadores. Já as 
características de aroma e textura se devem a reação de Maillard que ocorre durante o assamento, que também é ocasionada devido a presença do açúcar invertido que por ser um açúcar redutor reage com aminoácidos e proteínas, agregando ao biscoito aroma e textura mais agradáveis.

\section{Conclusões}

Conclui-se que a adição de açúcar invertido na formulação de biscoitos tem grande influência positiva nas características de sabor, aroma e textura do produto, sendo que diante a análise sensorial o biscoito contendo este tipo de açúcar na formulação foi o mais preferido e teve estas características bastante observadas e elogiadas.

\section{Agradecimentos}

Ao Programa de Concessão de Bolsa de Incentivo ao Pesquisador da Universidade Estadual de Goiás (BIP), à Fundação de Amparo à Pesquisa do Estado de Goiás (FAPEG), ao Programa Institucional de Bolsas de Iniciação Científica do CNPq (PIBIC).

\section{Referências Bibliográficas}

1. Brasil. Ministério da Saúde. RDC nº 263, de 22 de setembro de 2005: Aprova o "regulamento técnico para produtos de cereais, amidos, farinhas e farelos", constante do Anexo desta Resolução. Diário Oficial da União, Brasília, 2005.

2. Azevedo, R. G. Melhoria do forneamento de biscoitos em forno á lenha com processo em batelada. 2007. Dissertação (Mestrado em Sistemas e Processos Industriais) - Universidade de Santa Cruz do Sul, Santa Cruz do Sul, 2007.

3. SEBRAE - Serviço Brasileiro de Apoio ás micro e pequenas empresas. Biscoitos caseiros não industrializados. Disponívelem:http://bis.sebrae.com.b r/GestorRepositorio/ ARQUIVOS_CHRONUS/bds/bds.n sf/16BDB863AB7F312A83257 53E005E2B03/\$File/NT0 003DB06.pdf . Acesso em 22/02/2014

4. Brasil, ANVISA - Agência Nacional de Vigilância Sanitária. Resolução CNNPA n 12,de 1978. Disponível em:http://www. anvisa.gov.br/anvisalegis/resol/12_78_b iscoitos.htm.

5. Bianchini, K. V ; Assumpção, R. M. A diferenciação de produtos na cadeia produtiva do açúcar: $\mathrm{O}$ processo de produção dos açúcares líquido e líquido invertido. $\mathbf{2 0 0 2}$
6. Manohar, R. S.; Haridas-Rao, P. Effect of sugars on the rheological characteristics of biscuit dough and quality of biscuits.Journal of the Science of Food and Agriculture, v. 75, n. 3, p. 383-390, 1997.

7. Silva, T. C. S. Relatório de estágio supervisionado: Indústria alimentícia Mendonça Ltda. 2010. Relatório de estágio (Engenharia de Alimentos) - Universidade Federal de Sergipe, Sergipe, 2010.

\section{Kelly N. Marra, Mikaele L. S. Santos* \& Daniela F. Silva}

Universidade Estadual de Goiás, Campus de Ciências Exatas e Tecnológicas-Henrique Santillo (CCET), Anápolis, Brasil

*E-mail: mickaellakatrina@gmail.com 